\title{
Palatal lifting prosthesis and velopharyngeal insufficiency: Preliminary report
}

\begin{abstract}
Ali Ibrahim Aboloyoun ${ }^{1}$, Sahar Ghorab², Mian Usman Farooq ${ }^{3}$
${ }^{1}$ Faculty of Medicine, Assuit University Egypt

${ }^{2}$ Faculty of oral and dental medicine Cairo University, Cairo, Egypt

${ }^{3}$ Health Research Department Alnoor

Specialist Hospital, Makkah, Saudi Arabia

Corresponding author:

Mian Usman Farooq

Department of Planning and

Development

Directorate General of Health Affairs

P.O. Box 6251

21955 Makkah, Saudi Arabia

drus76@yahoo.com

Tel.: + 966568232502

Fax.: + 96625665000

Received: 17 December 2012

Accepted: 2 April 2013

Objectives. Our study aimed to highlight the effectiveness of palatal lift prosthesis in patients with velopharyngeal insufficiency with previous operated cleft palate. Methods. This study was done undertaken January 2008 to December of 2009 in the Phoniatic unit of Alnoor Specialist Hospital, Makkah, Saudi Arabia. Ten patients of $\geq 8$ years to $\leq 10$ years of age, who had previously undergone surgery for cleft palate, with or without cleft lip, with no other systemic illness and normal intelligent quotient level, were selected and managed by palatal lift prosthesis. All the study subjects were subjected to auditory perceptual speech evaluation for assessment of the degree of hypernasality, compensatory articulator mechanisms, glottal and pharyngeal articulation, audible nasal emission, facial grimace and overall intelligibility of speech. Data were analyzed using SPSS version 16 . Results. The study included 10 subjects whose mean \pm standard deviation of age was $(8.9 \pm 0.9)$. On auditory speech perceptual evaluation after prosthesis application, significant improvement was found in glottal articulation $6(85.7 \%), \mathrm{p}=0.04$, facial grimace $6(85.7 \%) \mathrm{p}=0.04$, hyper nasality $10(10 \%) \mathrm{p}=0.008$, and speech intelligibility $9(90 \%) \mathrm{p}=0.008$. Conclusion. Young patients with repaired palatal cleft have significant improvement after application of palatal lift prosthesis.
\end{abstract}

Copyright (C) 2013 by

Academy of Sciences and Arts

of Bosnia and Herzegovina.

E-mail for permission to publish:

amabih@anubih.ba
Key words: Velopharyngeal insufficiency, Cleft palate, Cleft palate prosthesis.

\section{Introduction}

Velopharyngeal closure (VPC) is an important part of speech. The causes of hypernasality and velopharyngeal dysfunction (VPD), i.e., velopharyngeal insufficiency (VPI) and velopharyngeal incompetence, are many and range from structural causes with the velum, e.g., submucous cleft palate, short velum relative to the depth of the posterior pharyngeal wall, overt cleft palate, to neuromuscular problems, e.g., those observed in velocardiofacial (VCF) syndrome. Overt cleft palate, either before or after repair, is by far the most common cause of VPD. This condition occurs in approximately 1 of 2,000 live births. VPD has been reported in as many as $30-50 \%$ of patients following palate repair (1).

Orofacial clefts have an approximate rate of 1:500-1:550 births. In a large popu- 
lation-based study of 4,433 children born with orofacial cleft, the birth prevalence of nonsyndromic cleft lip, with or without cleft palate, was 0.77 per 1,000 births (cleft lip, 0.29/1,000; cleft palate, $0.48 / 1,000)$ and the prevalence of nonsyndromic cleft palate was 0.31 per 1,000 births. Children with orofacial cleft require surgical procedures and complex medical treatments (2). The data from the gulf region is deficient, but according to one systemic review of studies, in Saudi Arabia it ranged from 0.3-2.19 per 1,000 live births, in Oman1.5 per 1,000 live births, in Dubai, UAE 0.5 per 1,000 live and still births, while in Amman, Jordan 1.392.4 per 1,000 live births (3).

The end result is the passage of air into the nose during speech. In speech production, the audibility of air through the nose is termed as nasal escape, and the resulting speech is termed hypernasal or rhinolalia aperta (4). Severe VPI will often lead to compensatory speech behaviors, resulting in poor speech intelligibility (5). Diagnosis of VPI is made through taking a history and physical examination, perceptual speech assessment, nasoendoscopy and radiographic multiplanar videofluoroscopy (6). The use of prosthetic devices for correction of velopharyngeal insufficiency is an alternative treatment for patients with conditions that preclude surgery, and for those with hypo functional velopharynx. Prosthetic management requires close cooperation between the prosthodontist and a phoniatrician (speech pathologist) $(7,8)$.

Surgical repair of a cleft palate is performed by one year of age, in order to minimize speech articulation abnormalities. However, children develop VPI after cleft palate repair require active intervention, i.e., speech therapy, prosthetic management and/or surgery (9). Palatal lifts were used when adequate palatal length exists, and they physically reduce the distance the palate must traverse to produce adequate closure, acting as positioning device. Comprehensive management for these patients requires close interaction between the prosthodontist and the speech language therapist, to achieve the maximum benefit from the palatal lift prosthesis. Fluoroscopy and nasoendoscopy must be used in the design, placement and modification of the prosthesis, which provides a profound tool for diagnosis, the treatment plan and assessment of prognosis (10).

Our study aimed to highlight the effectiveness of palatal lift prosthesis in patients with velopharyngeal insufficiency who had previously undergone surgery for cleft palate, in order to measure the improvement of VPI.

\section{Methods}

This self controlled sequential experimental study was undertaken from January 2008 to December 2009, in the Phoniatic unit of Alnoor Specialist Hospital, Makkah, Saudi Arabia. Ten children aged 8 to 10 years, who had previously undergone surgery for cleft palate, with or without a cleft lip, no other systemic illness and normal intelligent quotient level, were selected as study subjects. Before the final selection of cases, the mouth mirror test was performed to decide if the case was a candidate for a palatal lift appliance or not.

\section{Palatal lift prosthesis was placed in the following steps}

Primary alginate impressions were undertaken and poured into a study cast, followed by a primary survey. The upper first and second deciduous molars or second deciduous molar and first permanent molar were prepared to receive casted bands, followed by secondary rubber-based impressions poured into master casts, which received alterations. The master cast was duplicated 
in the investment cast and then a wax pattern was made, spewed and cast. A metal skeleton was tried out the patient's mouth for metal adjustment, after finishing and polishing. An impression of the oro-pharyngeal border was then taken using a green stick compound for border molding and a rubber-base as the impression material, on the posterior border of the chrome-cobalt skeleton. It was then converted into acrylic resin, followed by a trial seating in the patient's mouth. The final functional impression was completed using a resilient liner in order to elevate the soft palate and cement the appliance using bands and resin cement. The patient was given a follow-up appointment with instructions for proper oral hygiene measurements. Figure 1-3

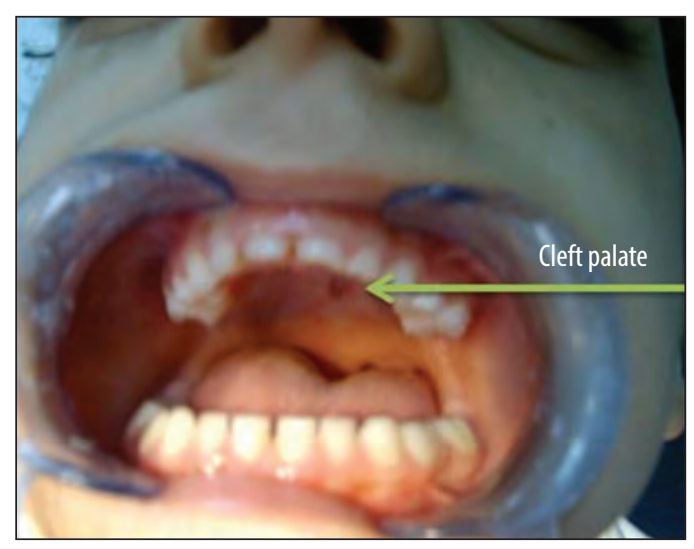

Figure 1 Case before appliance construction.

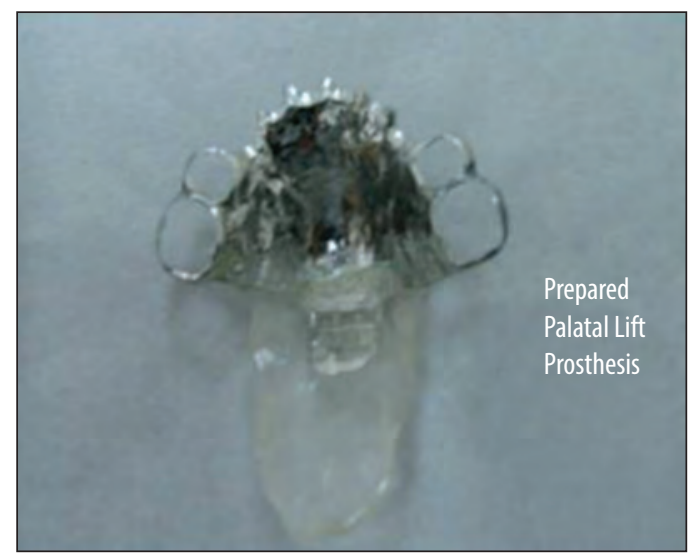

Figure 2 The finished palatal lift before relining.
Patients were evaluated pre-intervention and immediately post insertion, and given appointments for re-evaluation after 4872 hours of appliance application. The final data of re-evaluation considered in this study was collected after an adaptation period of about two months of appliance insertion. All the study subjects were subjected to auditory perceptual speech evaluation, for assessment of the degree of hypernasality, compensatory articulatory mechanisms, glottal and pharyngeal articulation, audible nasal emission, facial grimace and overall intelligibility of speech. Two simple clinical tests were undertaken for patients i.e., Gutzman's (A/I) test and Czermak's (cold mirror) test. Videonasoendoscopic evaluation was performed for patients using a fiber optic nasofibroscope coupled with high intensity light and recorded using digital Atmos system. Topical anesthetic gel was applied to the nasofibrolaryngoscope before insertion through the nasal cavity, to reach superior to the velopharyngeal port in order to assess movement of the velum, and the lateral and the posterior pharyngeal walls were observed while the patient repeated an oral speech sample, loaded with phonemes, which needed increased oral airflow (plosives and fricatives). Videoendoscopy offers the advantage of a lack of ionizing radiation in videofluroscopy and the ability to help in

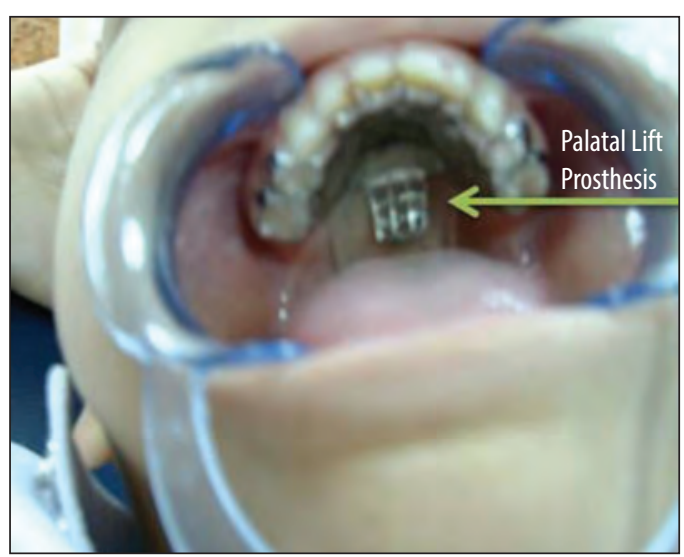

Figure 3 Palatal lift appliance in the patient's mouth. 
assessment of all structures at the same time (11). We classified improvement in clinical features when they became absent after appliance application, except nasality and speech intelligibility, where we differentiated it according to the decrease in the severity of features i.e., from severe to moderate, moderate to mild and mild to absent.

Written informed consent was taken from all the subjects' guardians, and hospital research committee endorsement was given for this research.

\section{Statistical analysis}

Data were analyzed using SPSS version 16 (SPSS Inc., Chicago, IL, USA). The data was subjected to descriptive analysis. The McNemars test with continuity correction was applied to categorical data, to analyze the proportions in repeated measurements (12). One directional $p$-value of $\leq 0.05$ was considered significant.

\section{Results}

The study included 10 subjects whose mean \pm standard deviation of age was $(8.9 \pm 0.9)$.
By auditory speech perceptual evaluation before the application of appliance, abnormal pharyngeal articulation and audible nasal emission was positive in $6(60 \%)$ subjects while facial grimace and abnormal glottal articulation was positive in $7(70 \%)$ subjects. Following application of the appliance and intensive speech therapy for 3-6 months for each case, it was found that: $6(85.7 \%)$ subjects improved their glottal articulation $(\mathrm{p}=0.04)$ and $6(85.7 \%)$ had facial grimace improvement $(\mathrm{p}=0.04)$. On the other hand, the A/I test and cold mirror tests were found positive in all subjects, with insignificant improvement in $4(40 \%)$ subjects after application of the appliance. Before the procedure, hypernasality was found mildly impaired in $3(30 \%)$ subjects and in them it was completely improved, 5 (50\%) subjects had improvement from moderate to mild and 2 (20\%) from severe to moderate $(\mathrm{p}=0.004)$ with the appliance. Moreover, speech intelligibility was found to be improved from mild $3(30 \%)$ to normal in two, from moderate 4 (40\%) to mild and from severe $3(30 \%)$ to moderate in all subjects $(\mathrm{p}=0.008)$. So the overall improvement in the last two features were (100\%) and (90\%) respectively.

Table 1 Speech evaluation before and after appliance insertion

\begin{tabular}{llll}
\hline \multirow{2}{*}{ Speech evaluation variables } & \multicolumn{1}{l}{ Before $(\mathrm{n}=10)$} & After & Significance \\
\cline { 2 - 3 } & Abnormality/ Positivity & Improvement & \multirow{2}{*}{$\mathrm{n}$-value* } \\
\cline { 2 - 4 } & $\mathrm{n}(\%)$ & $6 / 7(85.7)$ & $\chi^{2}=4.16 ; 0.04$ \\
\hline Glottal articulation & $7(70 \%)$ & $1 / 617)$ & $\mathrm{NS}{ }^{* *}$ \\
Pharyngeal articulation & $6(60)$ & $6 / 7(85.7)$ & $\chi^{2}=4.16 ; 0.04$ \\
Facial grimace & $7(70)$ & $3 / 6(50)$ & $\mathrm{NS}$ \\
Audible nasal emission & $6(60)$ & $4 / 10(40)$ & $\mathrm{NS}$ \\
Gutzman's A/I test & $10(100)$ & $4 / 10(40)$ & $\mathrm{NS}$ \\
Cold mirror test & $10(100)$ & $10 / 10(100)$ & $\chi^{2}=8.1 ; 0.008$ \\
Hyper nasality & $10(100)$ & $9 / 10(90 \%)$ & $\chi^{2}=7.1 ; 0.008$ \\
Speech intelligibility & $10(100)$ &
\end{tabular}




\section{Discussion}

Velopharyngeal (VP) incompetency occurs when the surgically repaired soft palate is of adequate length but of inadequate mobility to elevate to achieve velopharyngeal closure. Achieving VP closure, and thus optimal speech, is one of the primary goals of palatoplasty. The literature indicates that VP competence is achieved in only $70 \%$ to $90 \%$ of patients. This variability is most likely the result of the type of palatoplasty performed and differences in definitions and opinion regarding what constitutes VPI (13).

Palatal lift prosthesis covers the hard palate and extends posteriorly to engage the soft palate, and physically elevates and extends it to the proper position, to achieve closure. This prosthesis is most effective when the soft palate has little muscle tone and offers little resistance to elevation (14). Most patients with palatopharyngeal incompetency are treated surgically or with speech therapy, or both, but there are individuals who might benefit most from palatal lift prosthesis than from other treatments (10).

Before starting construction of palatal lifting appliance, the mouth mirror test was performed to determine the potential amount of force required to lift the soft palate to create the desired effect, prior to committing to lift fabrication. Usually, patients with little or no soft palate movement will present with flaccid paralysis of the soft palate muscles. The soft palate is easily displaced upward by pressing on it with a mouth mirror or tongue blade. If the soft palate resists displacement because of fibrosis or tonicity of the muscles, a palatal lift might not be successful. Too much force will be required to lift the palate and likely result in a lift that cannot be kept in place or in pressure irritation and ulceration of the soft palate mucosa, so the mouth mirror test is a quick indicator of the potential for success of the lift.

In our study there was highly significant improvement in hypernasality and speech intelligibility after application of a palatal lift prosthesis, and our results are somehow consistent with those of Sell et al, (15). Nevertheless, oral tone was achieved only in patients with mild hypernasality $3(30 \%)$, while no subject with moderate $5(50 \%)$ or severe 2 (20\%) hypernasality obtained oral tone. However, they improved towards mild and moderate, respectively. Similarly, we found improvement in 3 (50\%) in terms of audible nasal emission.

Pinto et al. (16) mentioned that speech intelligibility was significantly better after placement of the prosthesis for patients with VPI, after primary palatoplasty, and speech therapy was needed to eliminate any compensatory articulation production that had developed. In another study, seven patients with velopharyngeal dysfunction, secondary to a surgically corrected cleft palate, were subjected to palatal lift prosthesis. A significant decrease in nasal resonance and improvement in speech intelligibility was found (17).

The clinical effect of a speech appliance in improving velopharyngeal function during blowing may be caused by an increase in the reserve capacity of the levator muscle. An increased reserve capacity in levator activity may be effective in preventing fatigue of the muscles related to velopharyngeal function for speech (18).

\section{Conclusions}

Application of an appliance and intensive speech therapy gave significant benefit to the young subjects in improving their glottal articulation, facial grimace, hypernasality and speech intelligibility. To achieve maximum benefit from palatal lift prosthesis, the prosthodontist and the speech pathologist must co-operate, using the technology of fluoroscopy and nasoendoscopy in the design, placement and modification of the prosthesis. Ongoing intensive speech ther- 
apy is frequently necessary for patients receiving palatal lifts for further improvement in speech intelligibility, achieving accepted comprehensive speech.

Authors' contributions: Conception and design: AIA, SG, MUF; Acquisition of data: AIA, SG; Analysis and interpretation of data: MUF; Drafting the article: AIA, SG; Revising it critically for important intellectual content: AIA, SG.

Conflict of interest: The authors declare that they have no conflict of interest.

\section{References}

1. Biavati MJ, Sie K, Wiet GJ, Rocha-Worley G. Velopharyngeal Insufficiency [Internet]. New York NY, Emedicine, Medscape [updated: 2011 Sep 2; Cited 2012 Jan 30]. Available from: http://emedicine. medscape.com/article/873018-overview\#a0101.

2. Tolarova MM, Sie K, Wiet GJ, Rocha-Worley G. Pediatric Cleft Lip and Palate [Internet]. New York NY: Emedicine, Medscape [updated: 2009 Mar 23; Cited 2010 Dec 30]. Available from: http://emedicine.medscape.com/article/995535-overview

3. Sabbagh HJ, Mossey PA, Innes NPT. Prevalence of orofacial clefts in Saudi Arabia and neighboring countries: A systematic review. The Saudi Den J. 2012;24(1):3-12.

4. Gosain AK, Conley SF, Marks S, Larson DL. Submucous cleft palate: diagnostic methods and outcomes of surgical treatment. Plast Reconstruct Surg. 1996;97(7):1497-509.

5. Shprintzen RJ, Schwartz RH, Daniller A, Hoch L. Morphologic significance of bifid uvula. Pediatrics. 1985;75(3):553-61.

6. Rudnick EF, Sie KC. Velopharyngeal insufficiency: current concepts in diagnosis and management. Curr Opin Otolaryngol Head Neck Surg. 2008;16(6):530-5.

7. Lima-Gregio AM, Marino VC, Pegoraro-Krook MI, Barbosa PA, Aferri HC, Dutka Jde C. Nasalance and nasality at experimental velopharyn- geal openings in palatal prosthesis: a case study. J Appl Oral Sci. 2011;19(6):616-22.

8. Agarwal KK, Singh BP, Chand P, Patel C. Impact of delayed prosthetic treatment of velopharyngeal insufficiency on quality of life. Indian J Dent Res. 2011;22(2):356-8.

9. Dorf DS, Curtin JW. Early cleft palate repair and speech outcome. Plast Reconstr Surg. 1982;70(1):74-9.

10. Kumar S, Hegde V. Prosthodontics in velopharyngeal incompetence. J Indian Prosthodont Soc. 2007;7:12-6.

11. Patel PK, Grasseschi MF, McGraw EK, O’Gara MM, Ramaswamy R, Witt PD. Surgical Treatment of Velopharyngeal Dysfunction [Internet]. New York NY: Emedicine, Medscape [updated: 2011 Aug 11; Cited 2012 Jan 30]. Available from: http://emedicine.medscape.com/article/1279928overview\#aw2aab6b3.

12. Siegal S, Castellan NJ Jr. Nonparametric Statistics for the Behavioral Sciences. 2nd, ed. New York: McGraw-Hill; 1998. p. 75.

13. Furlow LT. Secondary cleft palate surgery. In: Grotting JC, ed. Reoperative esthetic and reconstructive plastic surgery. 1st ed. St. Louis, Missouri: Quality Medical Publishing; 1995. p. 799-846.

14. Reisberg DJ. Dental and prosthodontic care for patients with cleft or craniofacial conditions. Cleft Palate Craniofac J. 2000;37(6):534-7.

15. Sell D, Mars M, Worrell E. Process and outcome study of multidisciplinary prosthetic treatment for velopharyngeal dysfunction. Int J Lang Comm Dis. 2006;41(5):495-511.

16. Pinto JH, da Silva Dalben G, Pegoraro-Krook MI. Speech intelligibility of patients with cleft lip and palate after placement of speech prosthesis. Cleft Palate Craniofac J. 2007;44(6):635-41.

17. Raju H, Padmanabhan TV, Narayan A. Effect of a palatal lift prosthesis in individuals with velopharyngeal incompetence. Int J Prosthodont. 2009;22(6):579-85.

18. Tachimura T, Nohara K, Hara H, Wada T. Effect of placement of a speech appliance on levator veli palatini muscle activity during blowing. Cleft Palate Craniofac J. 1999;36(3):224-32. 